Original Research Article

\title{
Prevalence of insulin induced lipodystrophy in patients with diabetes mellitus in a tertiary care centre: a cross sectional study
}

\author{
Shravani Bezawada ${ }^{1}$, Anuradha H. V. ${ }^{1 *}$, Pramila Kalra ${ }^{2}$
}

\begin{abstract}
${ }^{1}$ Department of Pharmacology, ${ }^{2}$ Department of Endocrinology, M.S Ramaiah Medical College, Bangalore, Karnataka, India
\end{abstract}

Received: 19 January 2019 Accepted: 27 February 2019

*Correspondence to:

Dr. Anuradha H. V.,

Email: dr.anukiran@gmail.com

Copyright: (c) the author(s), publisher and licensee Medip Academy. This is an openaccess article distributed under the terms of the Creative Commons Attribution NonCommercial License, which permits unrestricted noncommercial use, distribution, and reproduction in any medium, provided the original work is properly cited.

\begin{abstract}
Background: Diabetes Mellitus is a spectrum of common metabolic disorders whose management mainly lies in treating the patients with oral hypoglycaemic drugs and insulin along with the dietary and lifestyle modifications. Lipodystrophy is the most neglected adverse drug effect caused by injecting insulin. The main objective of this study was to assess the prevalence of lipodystrophy at the insulin injection sites in patients suffering from diabetes mellitus (Type 1 and Type 2).

Methods: A cross-sectional study was conducted in the Department of Endocrinology on 250 diabetic patients taking insulin injections based on inclusion and exclusion criteria. The demographic features and anthropometric measurements were noted. Insulin injection sites were examined clinically by inspection and palpation for presence of swelling like lipodystrophy, injection marks and signs of allergy like erythema etc. Lipodystrophy was graded from 03 and denoted as lipohypertrophy or lipoatrophy. The results were tabulated and presented accordingly.

Results: In this study, out of 250 patients 17 (6.8\%) patients presented with insulin induced lipodystrophy. Lipohypertrophy was the most common presentation and only one case presented with lipoatrophy.

Conclusions: It can be concluded from the present study that lipodystrophy which is an important adverse effect due to insulin injection needs to be monitored regularly in every patient taking insulin for better control of glucose levels.
\end{abstract}

Keywords: Adverse drug reaction, Diabetes, Insulin, Lipodystrophy, Prevalence

\section{INTRODUCTION}

Diabetes Mellitus (DM) is a spectrum of common metabolic disorders caused due to genetic and environmental factors involving insufficient secretion of insulin, reduced responsiveness to endogenous or exogenous insulin. ${ }^{1}$ It leads to abnormal levels of glucose, changes in carbohydrate, fat and protein metabolism. It is predicted that by 2030 diabetes mellitus may afflict up to 79.4 million individuals in India, while China (42.3 million) and the United States (30.3 million) will also see significant increases in those affected by the disease. ${ }^{2}$

If it is not treated, diabetes can cause many complications. Diabetes can present with acute complications like diabetic ketoacidosis, non-ketotic hyperosmolar coma or death. Serious long-term complications include heart disease, stroke, chronic kidney failure, foot ulcers, and damage to the eyes. ${ }^{3}$ Management of diabetes mainly is based on maintaining the blood sugar levels as close as to normal, without causing low blood sugar. 
Dietary and life style modifications are of utmost importance to maintain adequate glucose control. ${ }^{3}$ Various anti-diabetic medications like sulfonylureas, biguanides, thiazolidinediones, alpha-glucosidase inhibitors, dipeptidyl peptidase-4 Inhibitors (DPP-4), peptide analogues and insulin are being prescribed for treating type 2 DM. ${ }^{3}$ The oral anti-diabetic medications mainly function either as insulin secretagogues or help to overcome the resistance due to insulin. ${ }^{4}$

There are newer preparations like Sodium glucose transport 2 (SGLT2) inhibitors which promote glucose elimination through urine and help to control the blood glucose levels. ${ }^{4}$ Insulin is the drug of choice in type 1 diabetes and also for treating type 2 diabetes along with other anti-diabetic medications. ${ }^{1}$ It can be given subcutaneously, either by injections or by an insulin pump and in emergency, it may also be given intravenously. ${ }^{5}$

In general, there are four types of insulin, characterized by the rate at which they are metabolized by the body. They are rapid/ultra-short acting insulin, short acting, intermediate acting and long acting insulin. ${ }^{4}$ Insulin can be given as single injection or as multiple injections either by syringes or through pens. ${ }^{6}$ It can either be given as monotherapy or in combination with oral hypoglycaemic agents (OHAs) as per the requirement of the patient. ${ }^{7}$

Insulin can cause adverse drug reactions (ADR) like hypoglycaemia, hypersensitivity reactions, immunologic, dermatologic, itching, lipodystrophy- lipohypertrophy / lipoatrophy, tremor, muscle weakness, weight gain, metabolic alterations like hypokalaemia and very rarely gastrointestinal upset. ${ }^{3,8}$ One of the important adverse drug reactions seen with insulin therapy is lipodystrophy. ${ }^{4}$

Lipodystrophies are heterogeneous group of disorders characterized by abnormal fat deposition. In Greek 'Lipo' means 'fat', and 'dystrophy' means 'abnormal or degenerative condition'. ${ }^{9}$ It could occur either due to genetic or acquired factors. Insulin therapy can lead to development of adverse drug reactions at the injection site like lipohypertrophy / lipoatrophy, bruising and allergic reactions etc., which can further lead to development of poor metabolic control and glycaemic variability. ${ }^{10}$

Lipohypertrophy develops due to the anabolic effect of insulin on local skin leading to fat and protein synthesis, on the contrary lipoatrophy results from local formations of complexes between the antigens and circulating antibodies due to complement activation. ${ }^{11}$ Lipodystrophy can be graded from 0-3 accordingly and classified either as lipohypertrophy or lipoatrophy. ${ }^{10}$ Multiple factors play role involving the technique of insulin injection leading to such adverse drug reaction. ${ }^{11}$

The areas where lipodystrophy is present are relatively painless, patients tend to inject in the same area again and again rather than moving to a new site. With the technological advances there has been increase in the number of patients diagnosed with diabetes mellitus and treated with insulin at early stages. ${ }^{11}$ Insulin absorption from these sites is unpredictable and can lead to erratic glycaemic levels and unpredictable hypoglycaemic attacks. It is important to recognize and manage these complications.

Individuals should be advised not to inject into areas of lipodystrophy until abnormal tissue returns to normal, which may take several months or years. ${ }^{11}$ Switching injections from areas of lipohypertrophy to normal tissue often leads to a decrease in the requirement of dose of insulin. The amount of change varies from one individual to another and should be based on the frequent blood glucose measurements. Hence there is a need to understand the prevalence of lipodystrophy in Indian scenario.

Objective of the study was to assess prevalence of insulin induced lipodystrophy type 1 and type 2 diabetic patients.

\section{METHODS}

A cross-sectional study was conducted among the 250 diabetic patients who visited the Department of Endocrinology at M.S Ramaiah Medical College and Hospital for a period of one year. A written informed consent was taken from all the patients who were willing to participate in the study. General demographic data, anthropometric measurements, body mass index (BMI), $\mathrm{HbA1c}$, fasting and postprandial blood sugars, lipid profile were noted. The insulin injection sites were examined for presence of swelling, injection marks, and signs of allergy like erythema, pruritus, induration, nodules, abscess and loss of subcutaneous tissue.

The examination of injection site was done clinically by inspection and palpation method. If lipodystrophy, was present it was graded from 0-3 accordingly and classified either as lipohypertrophy or lipoatrophy. The opposite side of the body part was examined for comparison. The results of the study were further interpreted based on the information acquired.

All the quantitative variables like age, duration of diabetes mellitus, BMI etc., were presented using descriptive statistics like mean, median, range and standard deviation. All the qualitative variables like frequency of insulin injections, gender etc., were presented using frequencies and percentages.

\section{Inclusion criteria}

- $\quad$ Patients aged 18yrs and above.

- $\quad$ Patients presented with diabetes mellitus (type 1 and type 2).

- $\quad$ Patients on insulin therapy for a minimum period of 4 weeks.

- Patients who gave written informed consent for the study. 


\section{Exclusion criteria}

- $\quad$ Pregnant women and gestational diabetic women.

- Morbid obesity with BMI $>40$ kg/m2 .

- Patients with secondary diabetes.

- Patients who have undergone liposuction or bariatric surgeries previously.

- Chronic alcoholics.

- Patients with generalized lipodystrophy due to genetic or familial diseases.

- $\quad$ Patients on drugs like antiretroviral therapy, steroids, growth hormone, iron dextran, vaccines, penicillin etc.

\section{Sample estimation}

Based on the previous study conducted by Mo'men $\mathrm{Al}$ Ajlouni, Mousa Abujbara et al, it was found that the overall prevalence of lipodystrophy mainly lipohypertrophy was $37.3 \%$ in patients presenting with type 2 diabetes mellitus. In the present study, sample size was calculated considering the absolute precision of $6 \%$ and with a desired confidence level of $95 \%$. The sample size worked out was to be 250 diabetic patients.

\section{RESULTS}

This study involved 250 diabetic patients on insulin therapy with predominance of male patients (142) as compared to females (108) (Table 1). Patients above the age of 18 years were included in the study with a mean age of $55 \pm 13.8$ years. In Figure 1 the pie chart depicts the percentage of prevalence of insulin induced lipodystrophy wherein $6.8 \%$ of the entire patient population presented with lipodystrophy. There were different grades of lipodystrophy in patients showing positive signs of lipodystrophy (Figure 2). Seventeen patients were detected to be lipodystrophy positive with twelve patients commonly presenting with grade 1 lipodystrophy (Figure 2). The gender distribution of insulin induced lipodystrophy is presented and out of 17 lipodystrophic patients, $65 \%$ were males and $35 \%$ were females (Figure $3)$.

Table 1: Demographic data of diabetic patients on insulin therapy.

\begin{tabular}{|ll|}
\hline Characters & $\begin{array}{l}\text { Number of patients } \\
\text { (Percentages) }\end{array}$ \\
\hline Females & $108(43 \%)$ \\
\hline Males & $142(57 \%)$ \\
\hline Age range & $18-89$ years \\
\hline Mean age & $55 \pm 13.8$ years \\
\hline History of smoking & $65(26 \%)$ \\
\hline History of alcohol intake & $70(28 \%)$ \\
\hline Type of Diabetes & Type $1-5$ patients \\
\hline Family history of DM & Type $2-245$ patients \\
\hline Mean duration of DM & $13 \pm 8.33$ years \\
\hline
\end{tabular}

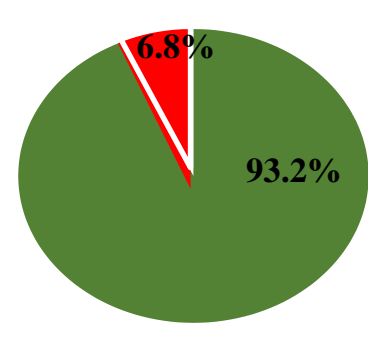

- NEGATIVE $\quad$ POSITIVE

Figure 1: Prevalence of insulin induced lipodystrophy.

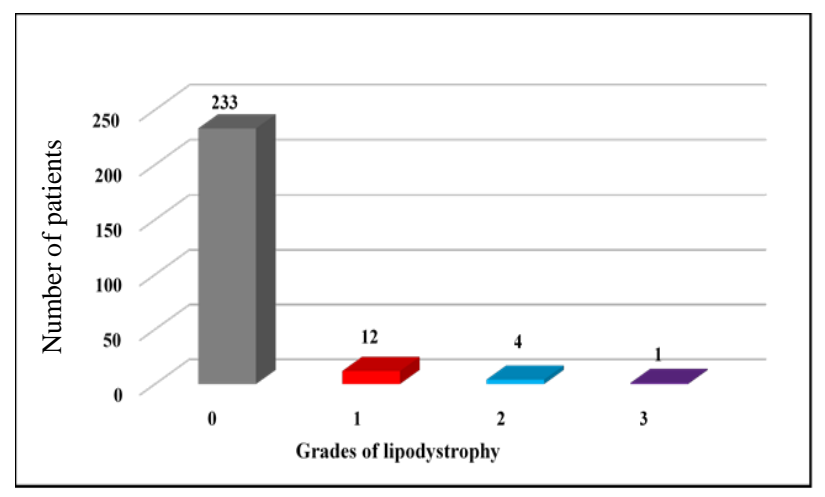

Figure 2: Frequency distribution of lipodystrophy grade.

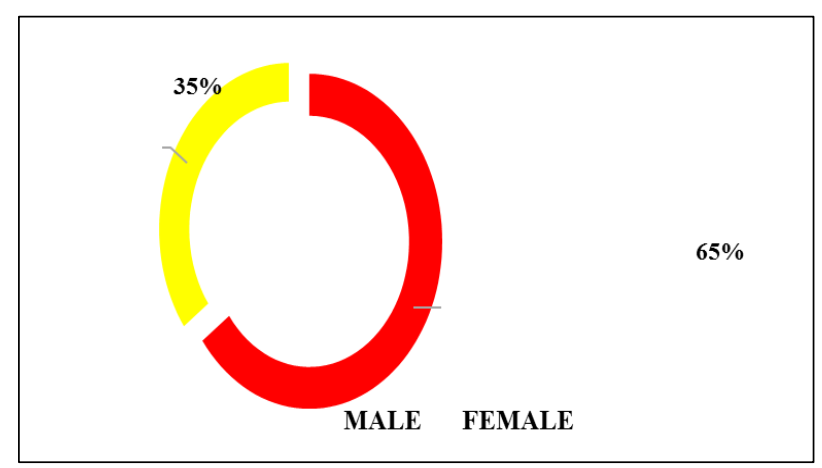

Figure 3: Gender distribution of insulin induced lipodystrophy.

Table 2: Number of insulin preparations/day.

\begin{tabular}{|ll|}
\hline Insulin preparations & $\begin{array}{l}\text { Number of patients } \\
\text { (percentage) }\end{array}$ \\
\hline Single & $161(64.4 \%)$ \\
\hline Multiple & $89(34.6 \%)$ \\
\hline
\end{tabular}

Detection of LH requires both visualization and palpation of injecting sites, as some lesions can be more easily felt than seen. In Figure 4A, section of the anterior aspect of abdomen is presented with lipohypertrophy (grade 2) and atrophy (grade 3) around the umbilicus is presented. In 
Figure 4B section of the right forearm of the patient is presented with lipohypertrophy (grade 2) and lipoatrophy (grade 3).

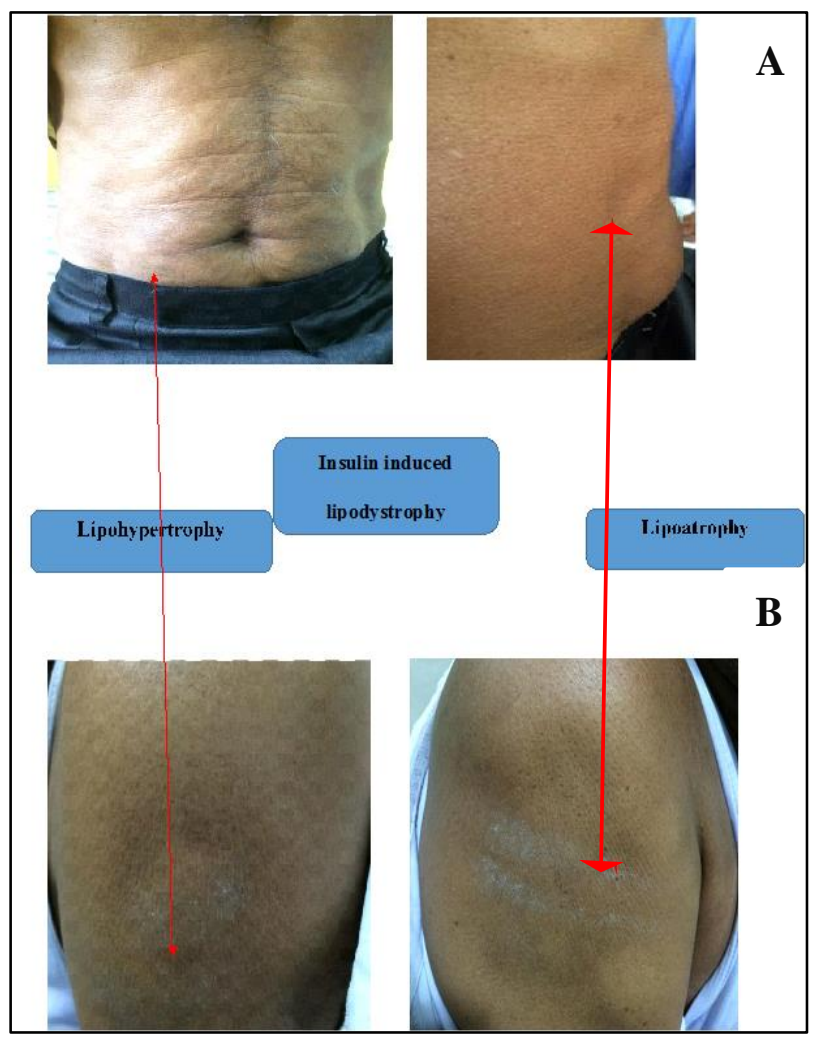

Figure 4 (A and B): Insulin induced lipodystrophyClinical appearance of insulin induced lipodystrophy.

\section{Examination of swelling - Lipodystrophy (Figure 4B)}

\section{Inspection}

On inspection there was a single, localized swelling measuring $2 \times 3 \mathrm{~cm}$, over the outer and middle aspect of the right arm. The swelling was oval in shape. The skin over the swelling and around it appeared normal with few injection marks. No signs of bruise/redness over the injection site. There are sites of inward cutaneous depression and palpable atrophy of subcutaneous fat tissue at the injection site.

\section{Palpation}

Inspectory findings were confirmed through palpatory technique. The swelling measured $2 \times 3 \mathrm{~cm}$. The swelling was non tender, non-febrile, smooth surface, soft to firm in consistency, movable in both direction, non-fluctuating and not adherent to underlying tissue or bone.

The Table 2 summaries the number of preparations of insulin therapy. Multiple preparations refer to different preparations administered at different times of the day. Sixty four percent of patients injected single insulin preparations (Table 2). The Table 3 explains about the frequency of various dose ranges of insulin, injected by diabetic patients. It was determined that 144 patients injected 31-60 $U$ of insulin per day. In the Table 4 the lipodystrophy and various preparations of insulin is presented. Lipodystrophy was found commonly in patients injecting intermediate insulin preparations followed by other preparation (long, short, ultra-short) $(\mathrm{p}=0.04)$ (Table 4).

Table 3: Doses of insulin injected per day.

\begin{tabular}{|ll|}
\hline Category of dose(units) / day & Number of patients \\
\hline$\leq 30$ & 78 \\
\hline $31-60$ & 144 \\
\hline $61-100$ & 24 \\
\hline$>100$ & 4 \\
\hline
\end{tabular}

Table 4: Prevalence of lipodystrophy with preparations of insulin.

\begin{tabular}{|c|c|c|c|}
\hline $\begin{array}{l}\text { Preparation } \\
\text { of insulin }\end{array}$ & $\begin{array}{l}\text { Number of } \\
\text { patients with } \\
\text { lipodystrophy }\end{array}$ & $\begin{array}{l}\text { Number of } \\
\text { patients } \\
\text { without } \\
\text { lipodystrophy }\end{array}$ & $\begin{array}{l}\mathbf{p} \\
\text { value }\end{array}$ \\
\hline Intermediate & 11 & 123 & \multirow{13}{*}{0.04} \\
\hline Ultrashort & 3 & 11 & \\
\hline $\begin{array}{l}\text { Ultrashort + } \\
\text { Short }\end{array}$ & 1 & 1 & \\
\hline $\begin{array}{l}\text { Ultrashort + } \\
\text { Long }\end{array}$ & 1 & 11 & \\
\hline $\begin{array}{l}\text { Short }+ \\
\text { Intermediate }\end{array}$ & 1 & 63 & \\
\hline Short & 0 & 10 & \\
\hline Long & 0 & 2 & \\
\hline $\begin{array}{l}\text { Ultrashort + } \\
\text { Intermediate }\end{array}$ & 0 & 4 & \\
\hline $\begin{array}{l}\text { Short + } \\
\text { Long }\end{array}$ & 0 & 8 & \\
\hline $\begin{array}{l}\text { Intermediate } \\
+ \text { Long }\end{array}$ & 0 & 0 & \\
\hline $\begin{array}{l}\text { Short + } \\
\text { Short }\end{array}$ & 0 & 0 & \\
\hline $\begin{array}{l}\text { Intermediate } \\
+ \\
\text { Intermediate }\end{array}$ & 0 & 0 & \\
\hline Total & 17 & 233 & \\
\hline
\end{tabular}

Figure 5 summaries that out of various sites of insulin injection by diabetic patients; arm-thigh, abdomen-thigh and abdomen-arm-thigh were the most commonly injected areas. Majority of the patients injected insulin in their arms - thighs $(n=87)$, abdomen-thighs $(n=79)$ and then in the abdomen-arm-thigh $(n=42)$ (Figure 5). In the Figure 6 the graph depicts the various preparations of insulin administered by diabetic patients. Combination refers to the combination of the insulin preparations given together either as ultra-short plus intermediate insulin OR long plus short acting insulin OR intermediate plus short acting 
insulin. Majority of patients injected intermediate acting insulin preparation.

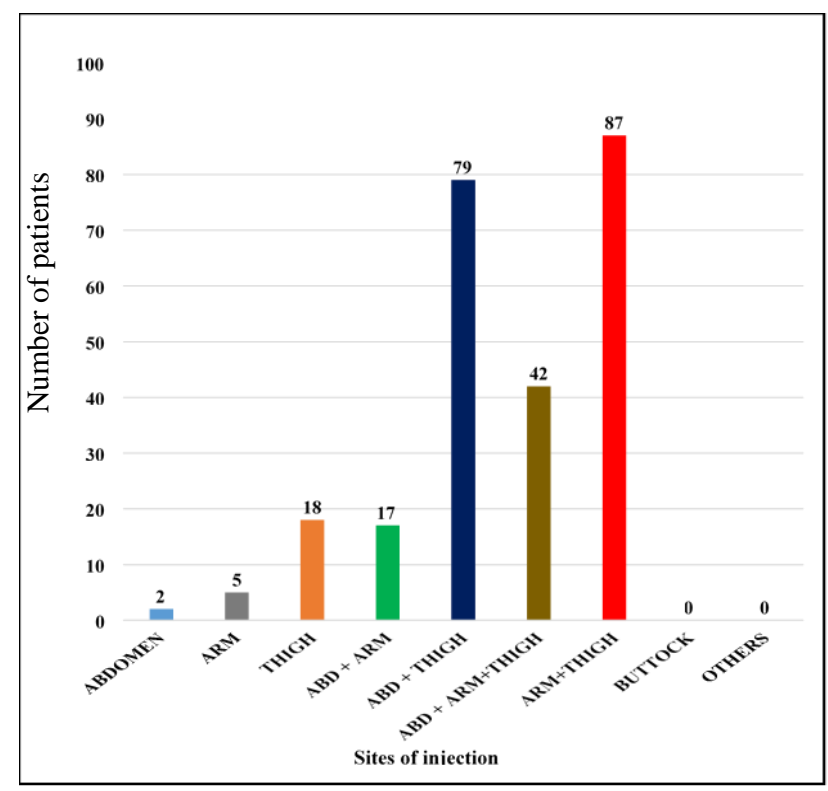

Figure 5: Sites of insulin injection administration.

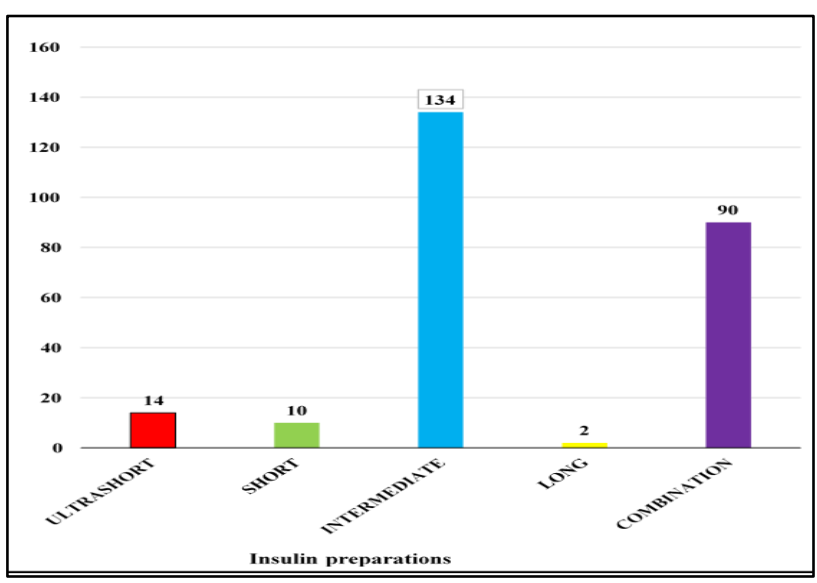

Figure 6: Distribution of insulin preparations among diabetic patients.

\section{DISCUSSION}

Out of 250 diabetic patients on insulin therapy there was predominance of male patients (142) as compared to females (108) (Table 1). Patients above the age of 18 years were included in the study with a mean age of $55 \pm 13.8$ years. In the present study the prevalence of insulin induced lipodystrophy was found to be $6.8 \% \quad(n=17)$ (Figure 1). The prevalence rates of LH in insulin-treated patients with Type 2 DM varied in different studies. In a study conducted by Al Ajouni et al, lipohypertrophy was observed in $37.3 \%$ of insulin treated patients with Type 2 DM. ${ }^{10}$

Insulin induced lipohypertrophy ( $\mathrm{LH}$ ) denotes to a benign tumor like swelling of fatty tissue at the injection site secondary to lipogenic effect of insulin, whereas lipoatrophy is considered as an adverse immunological side effect of insulin therapy. With discovery of recombinant human insulin, lipoatrophy has nearly disappeared, but lipohypertrophy still continues to be a serious local problem of insulin therapy. Injection into lipodystrophied sites, results in an erratic absorption of the drug, leading to glycaemic variability making it difficult to achieve suitable metabolic control. ${ }^{12}$

Treatment of insulin induced lipodystrophy include subcutaneous co-administration of corticosteroid with insulin, changing between different insulin preparations, rotation of injection sites, change of needles or syringes/pens, appropriate storage of insulin, changing the mode of insulin delivery, mast cell stabilizing therapy with topical $4 \%$ sodium cromolyn has been reported to reverse early and prevent new lipoatrophic lesions, soft tissue augmentation using a variety of permanent and nonpermanent fillers is also an option for cosmetic improvement of localized lipoatrophy. ${ }^{13}$

In a study conducted by Hauner et al., and Kashi et al., prevalence of LH was reported to be $3.6 \%$ and $14.5 \%$ of the diabetic patients, respectively. ${ }^{14,15}$ However, a much higher rate $(64.4 \%)$ was reported by a more recent study conducted by Blanco et al. ${ }^{16}$ Lipohypertrophy was described by inspection and palpatory methods as explained by $\mathrm{Al}$ Ajlouni $\mathrm{M}$ et al, Gentile $\mathrm{S}$ et al, and by the guidelines for examination of a swelling. ${ }^{10,17,18}$

Detection of $\mathrm{LH}$ requires both visualization and palpation of injecting sites, as some lesions can be more easily felt than seen. In Figure 4A section of the anterior aspect of abdomen presented with lipohypertrophy (grade 2) and atrophy (grade 3) around the umbilicus. In Figure 4B section of the right forearm of the patient presented with lipohypertrophy (grade 2) and lipoatrophy (grade 3).

Diabetic patients most commonly suffered from lipohypertrophy as compared to lipoatrophy. Lipodystrophy was graded between 0-3 and majority of the cases were of grade 1 -visible hypertrophy of fat tissue but palpably normal consistency. In a study conducted by $\mathrm{Al}$ Ajouni et al., lipohypertrophy in diabetic patients with insulin therapy were of grade $1,27.4 \%$; grade $2,9.7 \%$; and grade $3,0.2 \% .{ }^{10}$ Patients who were lipodystrophic were mainly males $(65 \%)$ (Figure 3), however gender differentiation and lipodystrophy cannot be attributed as it is depended on the number of male/female patients available in that particular period of time.

Majority of the patients injected insulin in their arms thighs $(n=87)$, abdomen-thighs $(n=79)$ and then in the abdomen-arm-thigh $(\mathrm{n}=42)$ (Figure 5). The administration of injection was mainly done either by oneself or by their relatives in these sites. Lipodystrophy was found mainly on abdominal and arms injection site.

Sixty four percent of patients injected single insulin 
preparations (Table 2). It was found that $40 \%$ of the diabetic patients with administering insulin more than twice daily irrespective of the insulin preparations. The average dose range in these patients was found to be between 31-60 units per day for most of the patients based on their blood glucose levels (Table 3 ). In the present study patients with lipodystrophy were injecting 31-60 U of insulin on an average daily basis. The worldwide Inter globe technology quotient data showed a strong association between the presence of $\mathrm{LH}$ and the total daily dose of insulin. Over 10 IU of insulin on an average was consumed in the LH positive versus LH negative population. ${ }^{19,20}$

Ninety out of 250 patients administered combination preparations of insulin, followed by intermediate acting insulin preparations and regular insulin (Figure 6). In a study conducted by Nikky Jain et al, majority of the patients 109 (90.83\%) were prescribed with regular/short acting human insulin and $11(9.16 \%)$ were prescribed with a combination of isophane and regular insulin. ${ }^{21} \mathrm{~A}$ similar study was conducted in Sree Ramachandra University by Harikrishnan KV et al., revealed that, 280 out of 350 patients administered combination of isophane and regular insulin whereas, 49 patients administered regular/short acting human insulin and the rest of the patients injected combination of regular insulin with isophane-regular insulin. ${ }^{22}$ In the present study, Lipodystrophy was found commonly in patients injecting intermediate insulin preparations followed by other preparation (long, short, ultra-short) $(\mathrm{p}=0.04)$ (Table4).

\section{CONCLUSION}

Prevalence of insulin induced lipodystrophy was $6.8 \%$ in diabetic patients. Grade 1 lipodystrophy was the most common presentation in these patients with slightly increased preponderance in males. The observations of the present study have generated information about prevalence of insulin induced lipodystrophy.

Hence, it can be concluded that active surveillance of adverse reaction like insulin induced lipodystrophy should be done as it is preventable; which further could help in avoiding variability in glycaemic levels among diabetic patients who are on long term insulin therapy. Diabetic patients and their relatives should be well educated with respect to the appropriate technique of insulin.

\section{Funding: No funding sources}

Conflict of interest: None declared

Ethical approval: The study was approved by the Institutional Ethics Committee

\section{REFERENCES}

1. American Diabetes Association. Diagnosis and Classification of Diabetes Mellitus. Diabetes Care. 2012;35(1):64S-71S.
2. Kaveeshwar S. The current state of diabetes mellitus in India. Australasian Med J. 2014;7(1):45-8.

3. Alvin C, David D'A. Endocrine Pancreas and Pharmacotherapy of Diabetes Mellitus and hypoglycemia. In: Bruton L, Chabner B, Knollman B. Goodman and Gilman's the pharmacological basis of therapeutics. $12^{\text {th }}$ ed. New York: Mc Graw- Hill Company; 2014:1144-1166.

4. Tripathi K. Essentials of medical pharmacology. $7^{\text {th }}$ ed. Jaypee; 2013:258-278.

5. Kansra UC, Sircar. Insulin Therapy: Practical Points. Journal, Indian Academy of Clinical Medicine. 2000;1(3):245-51.

6. DK M. Patient education: Diabetes mellitus type 1: Insulin treatment (Beyond the Basics); 2017. Available at: https://www.uptodate.com/contents/diabetesmellitus-type-1-insulin-treatment-beyond-the-basics. Cited on 13 August 2017.

7. Goudswaard AN, Furlong NJ, Valk GD, Stolk RP, Rutten GE. Insulin monotherapy versus combinations of insulin with oral hypoglycaemic agents in patients with type 2 diabetes mellitus. Cochrane Database of Systematic Reviews. 2004;4.Art. No: CD003418.

8. Chaudhury A, Duvoor C, Reddy DV, Kraleti S, Chada A, Ravilla R, et al. Clinical Review of Antidiabetic Drugs: Implications for Type 2 Diabetes Mellitus Management. Frontiers in Endocrinology. 2017;8(6):1-12.

9. James WD, Berger T. Clinical Dermatology. $10^{\text {th }}$ ed. Elsevier Health Sciences; 2006:538-541.

10. Al Ajlouni M, Abujbara M, Batieha A, Ajlouni K. Prevalence of Lipohypertrophy and associated risk factors in Insulin-treated patients with Type 2 Diabetes Mellitus. Int $\mathrm{J}$ Endocrinology Metabolism. 2015;13(2):E20776. Available at: Http://Www.Ncbi.Nlm.Nih.Gov/Pmc/Articles/PMC4 397947. Cited on 13 August 2017.

11. Kadiyala P, Walton S, Sathyapalan T. Insulin Induced Lipodystrophy. Bri J Diab Vascu Dise. 2014;14(4):131-3.

12. Mokta J, Mokta K, Panda P. Insulin lipodystrophy and lipohypertrophy. Ind $\mathrm{J}$ Endocrinol Metabol. 2013;17(4):773.

13. Breznik V, Kokol R, Luzar B, Miljkovic J. InsulinInduced Localized Lipoatrophy. Department Acta Dermatovenerol APA. 2013;22:83-5.

14. Hauner H, Stockamp B, Haastert B. Prevalence of Lipohypertrophy In Insulin- Treated Diabetic Patients And Predisposing Factors. Exp Clin Endocrinol Diabetes. 1996;104(2):106-10.

15. Kashi Z, Haiheydan Z, Akha O, Akbarzadeh S. Prevalence of lipodystrophy associated with recombinant insulin. Mazandaran Uni Med Sci J. 2008;18:9.

16. Blanco M, Hernández $M$, Strauss $K$, Amaya $M$. Prevalence and risk factors of lipohypertrophy in insulin-injecting patients with diabetes. Diabetes and Metabolism. 2013;39(5):445-53. 
17. Gentile S, Guarino G, Giancaterini A, Guida P, Strollo F. A suitable palpation technique allows to identify skin lipohypertrophic lesions in insulin-treated people with diabetes. Springer plus. 2016;5(1):3-4.52.

18. Das S. A Manual on Clinical Surgery. $12^{\text {th }}$ ed.; 2016:17-33.

19. Frid AH, Hirsch LJ, Menchoir AR, Morel D, Strauss K. Worldwide injection technique questionnaire study: population parameters and injection practices. Mayo Clinic Proc. 2016;91(9):1212-23.

20. Frid AH, Hirsch LJ, Menchoir AR, Morel D, Strauss K. Worldwide injection technique questionnaire study: injecting complications and role of the professional. Mayo Clinic Proc. 2016;91(9):1224-30.

21. Thomas NJ, Honey KR, Abraham A, Pandey M, Kumaraswamy M, Kumar BPS. A study on insulin usage among diabetic patient in a tertiary care teaching hospital. Indo Amer J Pharmace Resea. 2013;3(10):8474-8.

22. Harikrishnan KV, Rajasree R, Thomas N, Reghu R. Study of prescription pattern and insulin treatment in type 2 diabetic patients. Int J Pharm Pharmace Scien. 2012;4:328-30.

Cite this article as: Bezawada $\mathrm{S}$, Anuradha HV, Kalra P. Prevalence of insulin induced lipodystrophy in patients with diabetes mellitus in a tertiary care centre: a cross sectional study. Int J Basic Clin Pharmacol 2019;8:710-6. 